Article

\title{
The Water Footprint of Food Aid
}

\author{
Nicole Jackson ${ }^{1}$, Megan Konar ${ }^{1, *}$ and Arjen Y. Hoekstra ${ }^{2}$ \\ ${ }^{1}$ Department of Civil and Environmental Engineering, University of Illinois at Urbana-Champaign, \\ 205 N. Mathews, Urbana, IL 61801, USA; E-Mail: ndjackso@illinois.edu \\ ${ }^{2}$ University of Twente, P.O. Box 217, 7500-AE Enschede, The Netherlands; \\ E-Mail: A.Y.Hoekstra@utwente.nl \\ * Author to whom correspondence should be addressed; E-Mail: mkonar@illinois.edu; \\ Tel.: +217-333-8038.
}

Academic Editor: Marc A. Rosen

Received: 26 February 2015 / Accepted: 15 May 2015 / Published: 26 May 2015

\begin{abstract}
Food aid is a critical component of the global food system, particularly when emergency situations arise. For the first time, we evaluate the water footprint of food aid. To do this, we draw on food aid data from the World Food Programme and virtual water content estimates from WaterStat. We find that the total water footprint of food aid was $10 \mathrm{~km}^{3}$ in 2005, which represents approximately $0.5 \%$ of the water footprint of food trade and $2.0 \%$ of the water footprint of land grabbing (i.e., water appropriation associated with large agricultural land deals). The United States is by far the largest food aid donor and contributes $82 \%$ of the water footprint of food aid. The countries that receive the most water embodied in aid are Ethiopia, Sudan, North Korea, Bangladesh and Afghanistan. Notably, we find that there is significant overlap between countries that receive food aid and those that have their land grabbed. Multivariate regression results indicate that donor water footprints are driven by political and environmental variables, whereas recipient water footprints are driven by land grabbing and food indicators.
\end{abstract}

Keywords: food aid; water footprint; virtual water; water savings; water grabbing 


\section{Introduction}

The water footprint of the global food system has received considerable attention recently in an effort to address critical food and water problems that are global in nature [1]. The total water footprint of humanity has been estimated to be $9087 \mathrm{~km}^{3} \cdot$ year $^{-1}$ during the 1996-2005 period, of which agricultural production accounts for $92 \%$ [2]. The food system is globalized, such that the water footprint of international trade in agricultural products was $2038 \mathrm{~km}^{3} \cdot$ year ${ }^{-1}$ over the same 1996-2005 period [2] and continues to grow, roughly doubling over the last 25 years [3]. The water footprint of land grabbing has been presented as another important interaction in the global water-food system [4,5]. Food aid is also an international exchange of food commodities; its water footprint has not yet been evaluated.

Food aid is the voluntary transfer of food from one country to another for humanitarian purposes. Following World War II, the United States launched a major food aid program to help save lives and fight hunger by sending surplus grains around the world to people in need. As a result, it is estimated that U.S. food aid has saved hundreds of millions of people from malnutrition and starvation. In 2013 alone, the U.S. spent $\$ 1.7$ billion ( $<0.05 \%$ domestic budget) in order to provide over 46 million people across 56 countries food aid [6]. However, U.S. food aid is criticized for being a donor-driven system that promotes domestic interests, in which development is not the sole objective, and, in certain circumstances, actually promotes violence [7,8]. For these reasons, there have been recent attempts to reform U.S. food aid [9].

The World Food Programme (WFP) was developed as a multilateral food aid project to complement the United States' food aid program. It was initiated as a three-year project of the United Nations in 1961. It was converted to a full program in 1965 and serves as the global manager of food aid resources. The initial goal was to provide food during emergencies, and there was limited support for piloting developmental projects in exchange for food. WFP is eligible to receive support in the form of commodities, shipment assistance and money. A majority of its support comes from United Nations member countries, although there has been an increase in private donor support in recent years [10].

The "water footprint" concept was introduced by Hoekstra [11] to provide a framework to quantify the link between production and consumption of water resources. The water footprint of a product (also known as "virtual water content") is the total volume of water taken to produce the product throughout its lifecycle, expressed in terms of water volume per unit of product $[12,13]$. The water footprint of trade quantifies the volume of water embodied in international trade flows (also called "virtual water trade"), using product water footprints and data on commodity transfers between countries [3,14-16]. "Land grabbing" refers to the large-scale acquisitions of agricultural land by countries and corporations in other countries, often without consideration of the social, economic or environmental impacts [4]. The water footprint of land grabbing is the volume of water appropriated with the "grabbed" land [5], an increasingly important phenomenon as water-scarce countries look to expand their access to freshwater resources to produce food [4]. Food aid is another international exchange of food commodities, so it is important to quantify its associated water use, which is the main goal of this paper.

Freshwater resources are finite, so there is a ceiling to humanity's water footprint. For this reason, humanity will have to move towards sustainable water resources management. There are three pillars of sustainable freshwater allocation: water footprint caps per river basin, water footprint benchmarks per 
product and fair water footprint shares per community [17]. The water footprint caps per river basin would aim to ensure sustainable use of physical water resources within watersheds. The water footprint benchmarks per product will aim to incentivize producers to work towards a global standard of water use for their product. The fair water footprint share per community aims to enhance social equity [17], a key tenet of sustainability [18]. Thus, this paper, which evaluates the water footprint of food aid, contributes to our understanding of the equity of the water footprint of humanity.

International exchanges of food through trade have been shown to save water $[15,19,20]$, increasingly so over time [3,21]. International trade in staple foods has been estimated to save approximately $238 \mathrm{~km}^{3} \cdot$ year $^{-1}$, equivalent to $9 \%$ of global water use in agriculture in 2008 [3]. In fact, one of the first conceptions of virtual water trade was as a way for water-scarce countries to save their domestic water resources [22]. Similarly, countries that grab land to produce food are effectively directly outsourcing agricultural production in order to protect their own supply of water. Food aid is another channel through which food commodities are exchanged between nations. For this reason, it is important to understand the water efficiency of the food aid system and how it relates to other international exchanges of embodied water resources.

Multivariate regression analysis indicates that population, gross domestic product and geographical distance are correlated to international virtual water trade, with agricultural production in exporting nations also playing a role [23]. Understanding the key drivers of virtual water trade flows may prove useful in projecting future trade flows, potentially guiding decision makers [23]. To this end, a similar understanding of drivers of the water footprint of food aid would prove useful for understanding the system and evaluating the important relationships to consider for policy. For this reason, after we quantify the water footprint of food aid, we also conduct a regression analysis between the water embodied in aid and key environmental and social variables.

In this paper, we quantify the water footprint of food aid for the first time. To do this, we rely on data on food aid transfers from the World Food Programme [24] and product virtual water contents from WaterStat [13]. This enables us to address the following questions: (1) What is the total water footprint of food aid? (2) How does the water footprint of food aid compare with the water footprint of land grabbing, food trade and humanity? (3) What countries are the largest donors and recipients of water embodied in food aid? (4) Do food aid flows save water resources? (5) What variables are most closely correlated with the water footprint of food aid?

\section{Methods}

In this section, we describe the methodology that we employ to quantify the water footprint of food aid. First, we describe the food aid data. Second, we describe the estimates of product virtual water contents. Third, we explain how we use food aid data and product virtual water contents to quantify the water embodied in bilateral food aid transfers, the total water footprint of the food aid system and the water savings of the food aid system. Finally, we provide data sources for regression variables. 


\subsection{Food Aid Data}

The World Food Programme (WFP) administers the International Food Aid System (INTERFAIS). INTERFAIS was created to serve as a repository of global food aid data in terms of nutritional content and volume of food transfers [10,24]. INTERFAIS provides open access to food aid quantity reporting for 1988-2012 [24]. This data bank provides information on food aid volume by year, food aid type, recipient, donor, commodity and delivery mode [25].

The Supplementary Information lists the 194 countries that have participated in food aid between 1988-2012 (refer to File S1). However, note that the countries participating in food aid, either as donors or recipients, fluctuates annually. INTERFAIS also reports contributions from corporations, the WFP itself, other divisions of the United Nations and other non-governmental organizations. Food aid is predominantly comprised of 123 cereal and non-cereal commodities [26]. The full list of commodities typically provided through food aid is presented in the Supplementary Information (refer to File S2 for cereals and File S3 for non-cereals). There are three types of food aid: "emergency", "program" and "project". Table 1 summarizes each type. Figure 1 displays the food aid volume by type for the years 1988-2012. Program shipments dominated early reported years. More recently, emergency aid volumes have been larger than program and project-based food aid combined.

There are three food aid delivery modes: "direct transfer", "local purchase" and "triangular purchase". Figure 2 provides a schematic of each delivery mode. "Direct transfer" is defined to be when a donor country sends food that it produces directly to a recipient country. "Local purchase" is defined to be when a donor country provides financial assistance to the recipient country to purchase food within its local domestic markets. "Triangular purchase" is defined to be when a donor country provides financial assistance to the recipient country to purchase food from a third party country [27]. displays the volume of food aid by delivery mode for the years 1988-2012. All donation sources are considered for each mode. Note that the majority of food aid is delivered as direct transfer, although this mode has decreased in importance over the time period.

Table 1. Types of food aid [27]. WFP, World Food Programme.

\begin{tabular}{cc}
\hline Type & Description \\
\hline Program & Donated food or purchased at a reduced price for sale in the marketplace \\
Project & Zero cost food distributed by WFP or NGOs for development promotion \\
Emergency & Food distributed in response to a crisis \\
\hline
\end{tabular}




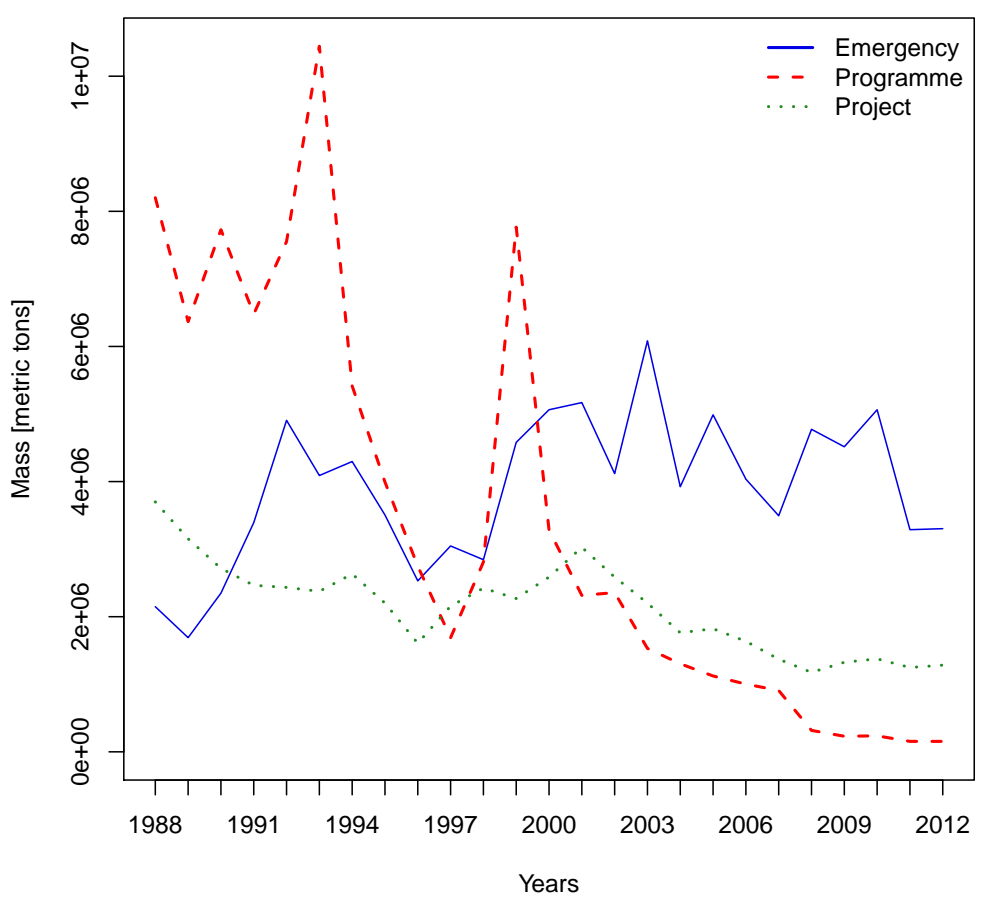

Figure 1. Food aid volume by food aid type from 1988-2012. Program shipments dominated early years. More recently, emergency aid volumes have been larger than the combination of program and project-based food aid combined.

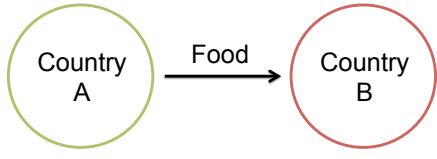

(a)

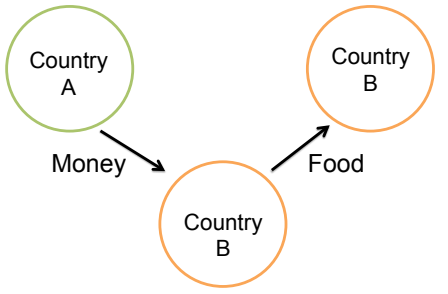

(b)

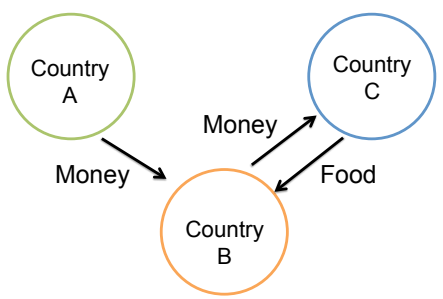

(c)

Figure 2. Delivery modes of food aid. (a) "Direct transfer" food aid is defined to be when Country A sends food directly to Country B; (b) "local purchase" food aid is defined to be when Country A sends money to Country B for it to purchase food within its domestic markets; (c) "triangular purchase" food aid is defined to be when Country A sends money to Country B to purchase food from Country C for distribution in Country B [24]. 


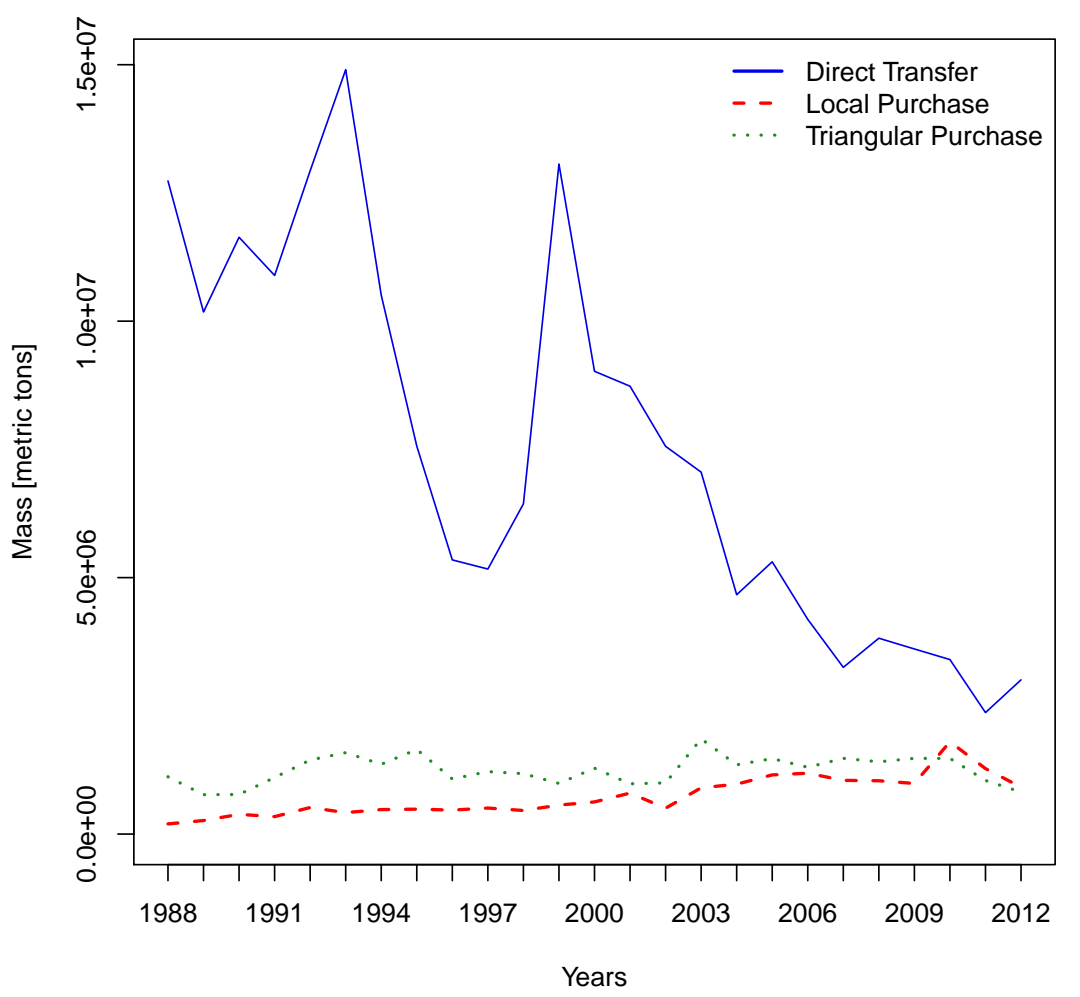

Figure 3. Food aid volume by delivery mode from 1988-2012. All donation sources (corporations, the WFP itself, other divisions of the United Nations and other non-governmental organizations) are considered. The majority of food aid is delivered as direct transfer, although this mode has decreased in importance over time. Triangular purchase volumes remain relatively constant, while local purchases have steadily increased.

\subsection{Virtual Water Content of Products}

In this section, we describe how we estimate the virtual water content of the INTERFAIS commodities. We retrieve estimates of product virtual water contents from the WaterStat database [13], provided by the Water Footprint Network. A grid-based dynamic water balance model [28] was employed to estimate the green, blue and grey water footprints for 146 primary crops and more than 200 derived crop commodities. These water footprints are provided at the country scale and averaged over the 1996-2005 time period. Details on model validation can be found in Mekonnen and Hoekstra [13].

The virtual water content of a product, $V W C$, is defined as:

$$
V W C=\frac{\sum_{s=1}^{k}(W U)_{s}}{P}
$$

where $W U$ is the water use, $s$ is the step in the production process and $P$ is the production volume [28]. In this way, $V W C$ estimates the volume of water per unit of food commodity [13]. Note that $V W C$ provides an estimate for each commodity and for each country of production. 
There is significant overlap in the commodities provided in the INTERFAIS food aid database and in the WaterStat virtual water content database. However, there are discrepancies in a few cases. For example, corn-soya blend is an INTERFAIS commodity (refer to SI) that does not exist in the WaterStat database. The virtual water content of "corn-soya blend" was computed by averaging the virtual water content of each component commodity (i.e., corn and soya). Some commodities in the INTERFAIS database were indicated as being fortified. In these instances, the non-fortified commodity served as a proxy for the entire fortified commodity. For example, to estimate the virtual water content of "soya-fortified maize meal", we averaged the virtual water contents of soya and maize meal. We provide the virtual water contents of all INTERFAIS commodities in the Supplementary Information (refer to File S4).

\subsection{Water Footprint of Food Aid}

In order to calculate the water footprint of food aid, we require information on food aid transfers and the virtual water content of food aid commodities. We combine INTERFAIS and WaterStat databases for this purpose, according to the following equation:

$$
A W F=\sum_{c, d, r} A_{c, d, r} * V W C_{c, d}
$$

where $A W F$ is the water footprint of food aid, $A$ is food aid as reported by INTERFAIS, $V W C$ is the product virtual water content as reported by WaterStat, $c$ is commodity, $d$ is donor country and $r$ is recipient country. Note that the total water footprint of food aid is summed across all donor-recipient relationships and commodities.

$V W C$ data from WaterStat are provided, averaged over the 1996-2005 time window. For this reason, we select INTERFAIS data on food aid transfers for the year 2005, to correspond to the last year of the WaterStat time period. We require information on the production location of the aid commodity in order to combine INTERFAIS and WaterStat data according to Equation (2). When local purchases are used, the commodity origin is the recipient country. Excluding this sort of aid from the study is reasonable, because it does not involve international virtual water flow. Conversely, the commodity origin location is not provided for the triangular purchase food aid delivery mode. Thus, we only consider direct transfer food aid between nations, which represents $66.9 \%$ of food aid donations from all sources in 2005 (refer to Figure 3).

Private food aid from corporate and non-governmental organizations is excluded from our calculation of the water footprint of food aid, because the origin countries of this type of food are not reported. These contributions represent $0.4 \%$ of all direct transfer donations in 2005 . Hence, $d$ and $r$ in Equation (2) refer only to nations that participate in the food aid system. However, the European Union (EU) reports food aid donations, so we average country-level $V W C$ estimates from WaterStat to arrive at an estimate for the EU. When these adjustments are made, we capture $66.5 \%$ of food aid donations for the 2005 aid year.

In this way, we estimate the water footprint of food aid for the year 2005. First, we estimate the water footprint of bilateral food aid flows by combining the INTERFAIS and WaterStat databases. Then, we estimate the total water footprint of the food aid system by summing across all commodities 
and donor-recipient pairs. Our estimate of the water footprint of food aid is conservative, because we only include direct transfer food aid flows and do not consider aid from corporations, the World Food Programme and non-governmental organizations.

\subsection{Water Savings Resulting from Food Aid}

International trade has been shown to save water resources [12,19,29], increasingly so over the last few decades [3]. The volume of water saved through the trade system is referred to as "trade-related water savings" $[16,19,30]$. A common misconception is that the trade-related water savings stems from the economic theory of comparative advantage, which it does not. The theory of comparative advantage is an economic theory of trade that requires inclusion of the opportunity cost of production [31]. A country has a comparative advantage in producing a good if the opportunity cost of producing that good in terms of other goods is lower in that country than it is in other countries [32]. The water savings metric does not consider opportunity cost, so it does not stem from the theory of comparative advantage. Instead, the water savings of trade focuses on the (physical) difference between water consumption with and without virtual water flow, assuming that without virtual water flow, the importing country will produce the product domestically.

We apply the identical water savings concept to food aid transfers. Just as in the case for trade, the concept of water savings as applied to aid measures the physical difference between water consumption with and without virtual water flows. The measure assumes that the recipient will produce the product domestically in the absence of food aid transfers. In food trade, there is a physical water savings when the exporting nation produces the product with less water per unit than the importing country. For food aid, there is a physical water savings when the donor country produces the product with less water per unit than the recipient country.

Here, we define the "aid-related water savings", $A W S$, as:

$$
A W S=\sum_{c, d, r} A_{c, d, r} *\left(V W C_{c, r}-V W C_{c, d}\right)
$$

where $A W S$ indicates the aid-related water savings, $A$ is the food aid as reported by INTERFAIS, $V W C$ is the product virtual water content as reported by WaterStat, $c$ is the aid commodity, $d$ is the donor nation and $r$ is the recipient nation.

The difference in water use efficiency between the donor and recipient nation is $V W C_{c, r}-V W C_{c, d}$, which is indexed by commodity. The difference in water use efficiency between two aid partners provides a theoretical measure of how much additional water would have been used had the commodity been produced in the recipient country, rather than in the donor country. When this difference is positive, it indicates that the aid relationship is saving water. When the difference is negative, the aid is inefficient in terms of water resources. This measure assumes that countries would produce to consume what they currently receive through aid, without any changes to agricultural water use efficiency. 


\subsection{Regression Variables and Methods}

To determine potential drivers of the water footprint of food aid, we perform a series of regressions. We obtain data from a variety of sources to determine potential correlations with the water footprint of food aid. Environmental and water availability and use indicators were obtained from the World Resources Institute Aqueduct database [33-35] and the Food Aid Organization (FAO) Information System on Water and Agriculture database, FAO AQUASTAT [36]. Food parameters were found in the WaterStat [13] and World Bank databases [37]. Political indicators were found through the World Bank Worldwide Governance Indicators database [38]. To proxy for water scarcity, we constructed a variable that is the ratio between the water footprint of production [2] and the total renewable water resources in each nation [36]. For each variable, the data point closest to the year 2005 was selected to match the food aid and water footprint data as closely as possible.

The Land Matrix database denotes land grabbing contracts between countries [39]. This database was used to determine the frequency of the participation of countries, either as investors or targets, in land grabbing arrangements. The Land Matrix denotes the arrangement as being intended, concluded or failed. All contracts were counted equally regardless of status. Countries were given credit for an occurrence even if multiple countries participated in a contract. We select data from the Land Matrix for the period 2003-2007 to coincide with the water footprint of food aid data.

We performed multivariate regression analysis. The base 10 logarithms were calculated for all data. Separate data frames were constructed for the donor and recipient water footprints, as well as all explanatory variables. We began with the null hypothesis that the collection of explanatory variables had no impact on either the donor or water footprint. We chose a 5\% significant level; the $p$-values were examined to determine which factors were either significant or highly significant. Only those identified as having either level of significance were retained in the reduced model. The multiple R-squared value was obtained for each regression to describe the goodness-of-fit of the explanatory variables for capturing food aid water footprints.

\section{Results and Discussion}

In this section, we describe our results and discuss their implications. First, we quantify the total water footprint of food aid in 2005 and compare with the water footprint of land grabbing, food trade and humanity. Second, we determine the countries that are the largest donors and recipients of water embodied in aid and compare with countries participating in land grabbing contracts. Third, we present regressions to elucidate potential drivers of the water footprint of food aid.

\subsection{The Water Footprint of Food Aid}

In 2005, 116 countries participated in the food aid system. These countries exchanged 55 unique commodities. Figure 4 presents the top 10 commodities by mass. Wheat, rice and maize are responsible for $55.8 \%$ of all commodities directly transferred.

The total water footprint of food aid is $10 \mathrm{~km}^{3} \cdot$ year $^{-1}$ in 2005 . Table 2 presents the water footprints of land grabbing [4], food trade [2] and humanity [2], for comparison with the water footprint of food 
aid. Food trade represents $22.4 \%$ of the total water footprint of humanity [2]. The water footprint of food aid represents $0.5 \%$ of the total water footprint of food trade $(=10 / 2038)$. The water footprint of food aid is $2.0 \%$ of the water footprint of land grabbing $(=10 / 490)$. Thus, the total water footprint of food aid represents a relatively insignificant fraction of the total water footprint of humanity $(=10 / 9087$ $=0.1 \%$ ). Despite being small in aggregate terms, food aid transfers and associated embodied water resources represent a critical resource to recipient countries in times of need.

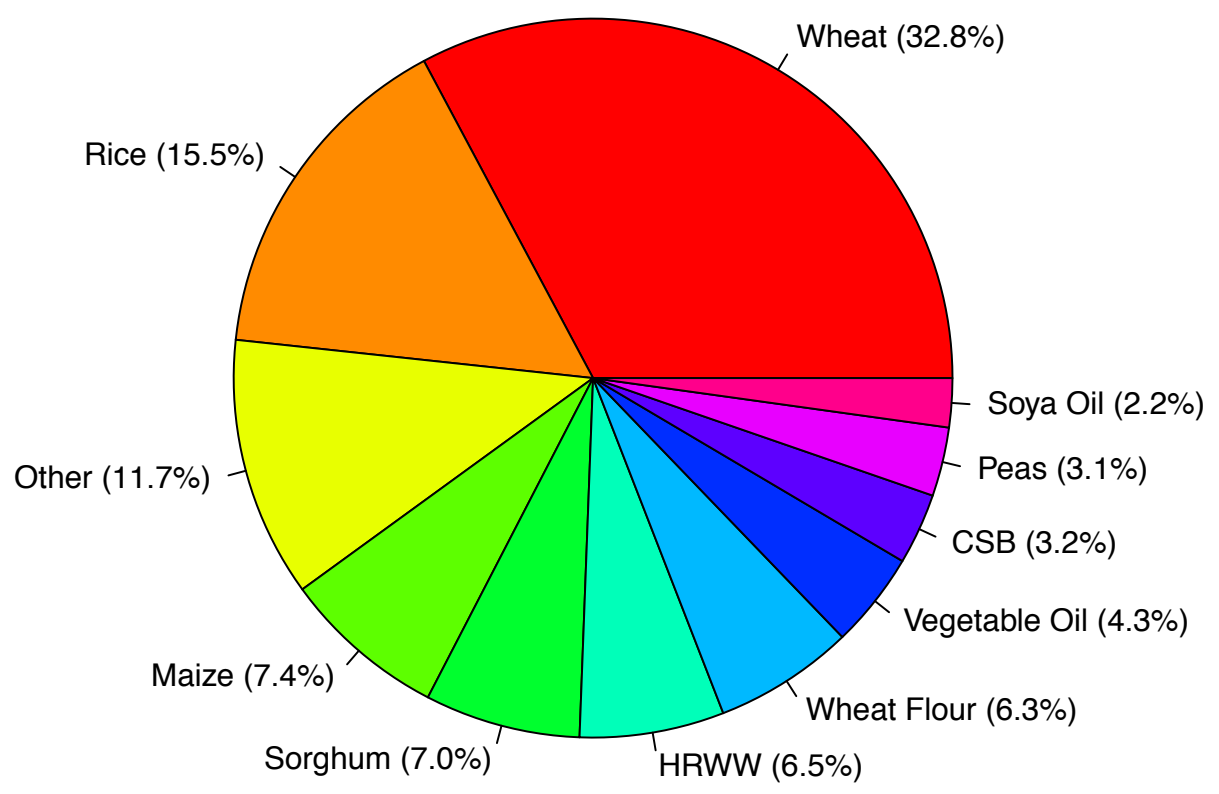

Figure 4. Top 10 food aid commodities by mass in 2005 . The total mass is $5.3 \times 10^{6}$ metric tons. Wheat, rice and maize are responsible for $55.8 \%$ of all commodities directly transferred. "HRWW" indicates hard red winter wheat and "CSB" indicates corn-soya blend. "Other" indicates the remaining 52 commodities. Note that percentages do not add up to $100 \%$ due to rounding.

Table 2. The water footprint of food aid as compared with land grabbing, international food trade and humanity.

\begin{tabular}{cc}
\hline & $\mathbf{k m}^{\mathbf{3}} \cdot \mathbf{Y e a r}^{-\mathbf{1}}$ \\
\hline Water Footprint of Food Aid (this study) & 10 \\
Water Footprint of Land Grabbing [4] & 490 \\
Water Footprint of International Food Trade [2] & 2038 \\
Water Footprint of Humanity [2] & 9087 \\
\hline
\end{tabular}

\subsection{Key Nations}

Figure 5 presents bilateral flows of water embodied in food aid flows. There were 86 recipient and 39 donor countries that participated in food aid flows. The United States (U.S.) is clearly the dominant donor of embodied water resources, both in terms of the number of connections and total volume. The U.S. has 
362 connections and donates $8.53 \mathrm{~km}^{3} \cdot$ year $^{-1}$ (82\% of all water resources embodied in aid in 2005). These connections are based on the the number of commodity-country pairs that the United States shares with recipient countries. The largest link in the system is from the U.S. to Ethiopia, which represents $1.9 \mathrm{~km}^{3} \cdot$ year $^{-1}$, or $18.2 \%$ of the total system. Food aid from the U.S. to Ethiopia principally occurs through wheat-based products; this comprises $76.4 \%$ of the food aid between the U.S. and Ethiopia.

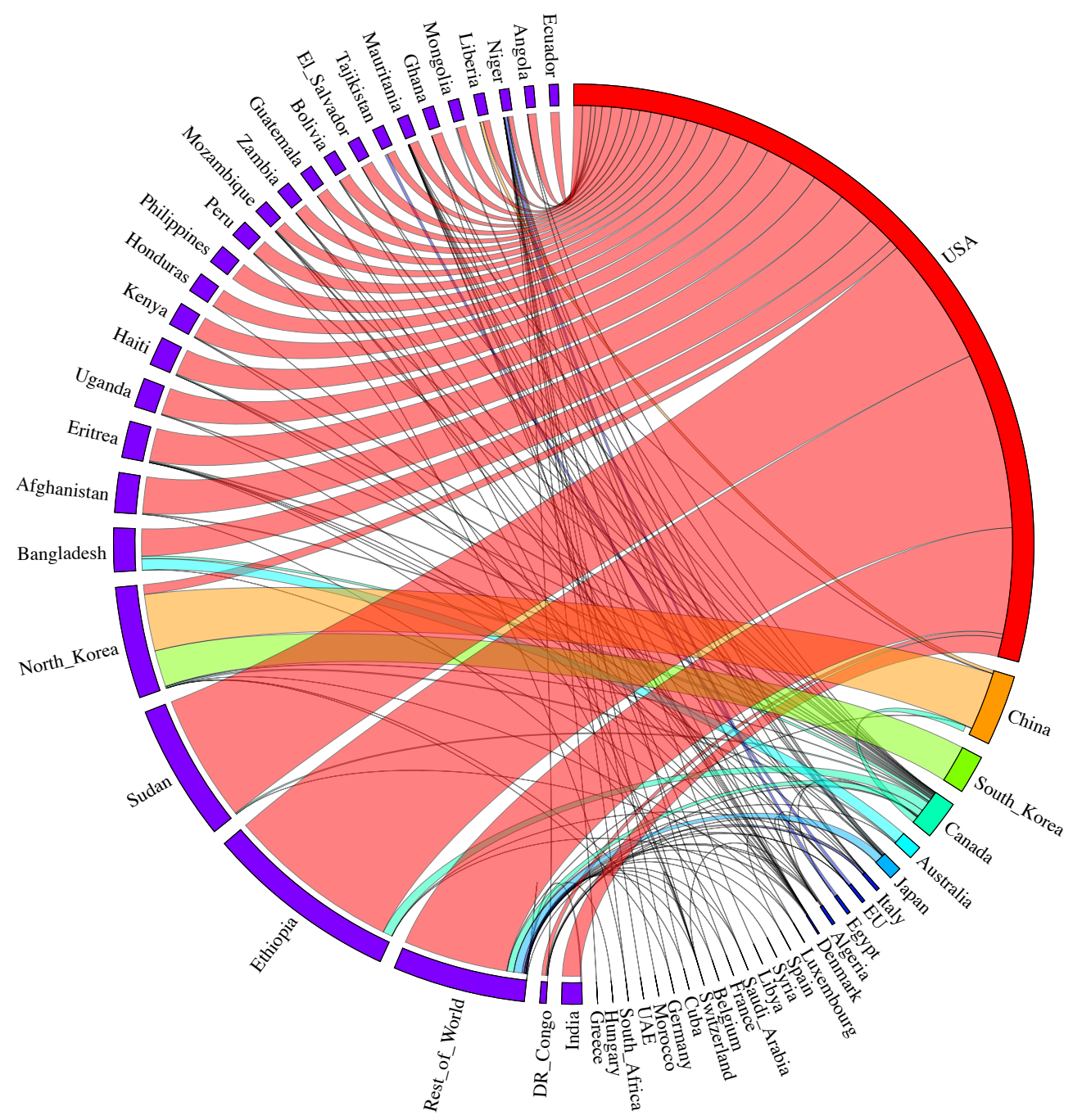

Figure 5. Water footprint of food aid. The total water footprint of food aid is $10 \mathrm{~km}^{3}$ in 2005 . All of the top donors and the top 25 recipients are illustrated. The size of the ribbon is scaled by the volume of the virtual water flow. The color of each ribbon corresponds to the donor country. The United States is the dominant donor, contributing $82 \%$ of all water embodied in food aid; it connects to every recipient country. All recipient countries are displayed in purple. From the USA clockwise to the rest of world, countries can be both donors and recipients. From Ethiopia clockwise, the countries are only recipients. "EU" indicates the European Union; "UAE" indicates the United Arab Emirates; and "rest of world" indicates the combined transfers of all remaining countries. This figure was created with network visualization software available at http://circos.ca, developed by Krzywinski et al. [40]. 
Table 3 provides rankings of the top 20 donors and recipients of water embodied in food aid. Again, it is clear that the U.S. is by far the largest contributor of embodied water resources. This finding is consistent with previous findings in the literature that highlight the U.S. as the world's largest virtual water exporter $[2,16]$. Ethiopia is the largest recipient of water resources embodied in food aid (19\%), closely followed by Sudan and North Korea. India is a unique country, as it is the only country within the top 20 donors and recipients of aid.

Table 3. Top 20 donors and recipients of water embodied in food aid in 2005 . Note that India is the only top donor and recipient.

\begin{tabular}{|c|c|c|c|c|c|c|}
\hline \multirow[b]{2}{*}{ Rank } & \multicolumn{3}{|c|}{ Donors } & \multicolumn{3}{|c|}{ Recipients } \\
\hline & Country & $\begin{array}{c}\text { Volume } \\
\left(\mathbf{k m}^{3} \cdot \text { Year }^{-1}\right)\end{array}$ & $\begin{array}{c}\text { Percent } \\
(\%)\end{array}$ & Country & $\begin{array}{c}\text { Volume } \\
\left(\mathbf{k m}^{3} \cdot \text { Year }^{-1}\right)\end{array}$ & $\begin{array}{c}\text { Percent } \\
(\%)\end{array}$ \\
\hline 1 & USA & 8.5295 & 81.8 & Ethiopia & 1.996 & 19.2 \\
\hline 2 & China & 0.6602 & 6.33 & Sudan & 1.405 & 13.5 \\
\hline 3 & South Korea & 0.3988 & 3.83 & North Korea & 1.147 & 11.0 \\
\hline 4 & Canada & 0.3979 & 3.82 & Bangladesh & 0.448 & 4.30 \\
\hline 5 & Australia & 0.1380 & 1.32 & Afghanistan & 0.408 & 3.91 \\
\hline 6 & Japan & 0.1323 & 1.27 & Eritrea & 0.375 & 3.59 \\
\hline 7 & Italy & 0.0348 & 0.33 & Uganda & 0.300 & 2.87 \\
\hline 8 & $\mathrm{EU}$ & 0.0328 & 0.31 & Haiti & 0.295 & 2.83 \\
\hline 9 & Egypt & 0.0289 & 0.28 & Kenya & 0.241 & 2.31 \\
\hline 10 & Algeria & 0.0206 & 0.20 & Honduras & 0.205 & 1.97 \\
\hline 11 & Denmark & 0.0173 & 0.17 & India & 0.197 & 1.89 \\
\hline 12 & India & 0.0124 & 0.12 & Philippines & 0.196 & 1.88 \\
\hline 13 & Luxembourg & 0.0050 & 0.05 & Peru & 0.178 & 1.71 \\
\hline 14 & Spain & 0.0029 & 0.03 & Mozambique & 0.142 & 1.36 \\
\hline 15 & Syria & 0.0025 & 0.02 & Zambia & 0.139 & 1.33 \\
\hline 16 & Libya & 0.0023 & 0.02 & Guatemala & 0.130 & 1.25 \\
\hline 17 & Saudi Arabia & 0.0013 & 0.01 & Bolivia & 0.129 & 1.24 \\
\hline 18 & France & 0.0011 & 0.01 & El Salvador & 0.124 & 1.19 \\
\hline 19 & Belgium & 0.0010 & 0.01 & Tajikistan & 0.119 & 1.14 \\
\hline 20 & Switzerland & 0.0009 & 0.01 & Mauritania & 0.116 & 1.11 \\
\hline- & Rest of the World & 0.0023 & 0.02 & Rest of the World & 2.136 & 20.5 \\
\hline
\end{tabular}

Europe is the world's largest virtual water importer [12] and contributes little to food aid. At the Union level, the EU contributed less than $1 \%$ of all water resources embodied in food aid. Even though, several member countries of the EU-Italy, Denmark, Luxembourg, France and Belgium-are individually located within the top 20 donating countries. The combined efforts of European countries, in total contributing $0.93 \%$ of the water embodied in global food aid, are still significantly less than the donations from the top five donors (i.e., the United States, China, South Korea, Canada and Australia). 
Many of the top food aid donors are also major food exporters. Conversely, the top recipients of food aid are completely dissimilar to major food importers. The net virtual water importers are concentrated in Europe, North Africa and the Middle East, whereas the top food aid recipients are largely represented by the poorest countries in East Africa, Asia and South America. This makes sense, since wealthier nations are able to participate in the trade system. However, the countries that are the largest recipients of food aid are not necessarily the smallest importers of food. To ascertain the correlation between top recipients of food aid and those that import the least amount of food, we obtained food import data from FAOSTAT [41]. We constructed four equally-spaced bins for food aid shipments $(n=86)$ and import data $(n=205)$. The top recipients were defined as those countries residing in the bin containing the 21 largest food aid received volumes. Countries importing the least amount of food were those residing in the bin containing the 51 smallest values. We find that the only intersecting country is Zambia, which received 70,600 metric tons of food aid and imported 2000 metric tons of food in 2005.

We evaluated the per capita external water footprint for those countries that receive food aid. To do this, we use data on the external water footprint, both per capita and total volume, from WaterStat for the year 2005. We created four equally-spaced bins to compare non-zero food aid recipient virtual water volumes $(n=80)$ to the non-zero per capita external water footprint of agricultural products for consumption $(n=173)$. The zero entries can be attributed to countries that received commodities for which there is no corresponding virtual water content or where no external water footprint of consumption data is available. The top recipients were defined as those countries residing in the bin containing the 20 largest food aid received volumes. Countries with the smallest external agricultural water footprints for consumption reside in the bin with the 43 smallest footprints. We find that $35 \%$ $(=7 / 20)$ of countries in the top quartile of food aid recipients were also in the bottom quartile of per capita external water footprint for agricultural consumption. The countries intersecting these quartiles are: Ethiopia, India, Mozambique, North Korea, Sudan, Uganda and Zambia.

In Table 4, we compare key participants in the food aid and land grabbing systems. In the food aid system, the U.S. is the principal donor, while Ethiopia is the key recipient. In the land grabbing system, China is the principal investor, while Cambodia is the major target. Again, India is an interesting case, since it is the only country to be ranked within the top 20 across all categories. As we might expect, several of the same countries participate as food aid donors and land grabbing investors. There are 11 such countries: the USA, China, Canada, Japan, Denmark, India, Luxembourg, Spain, Saudi Arabia, France and Belgium. Surprisingly, nine out of the top 20 countries are major food aid recipients and targets of land grabbing contracts: Ethiopia, Uganda, Kenya, India, Philippines, Peru, Mozambique, Zambia and Guatemala. Outside of the top 20, China, Egypt and Nigeria are the only countries to serve in all four roles. Half of all food aid recipients were land grabbing targets at least once, whereas $64 \%$ of all donor countries served as an investor at least once. Thus, the developed world is simultaneously donating food and securing land grabbing contracts, while the developing world, the recipient of most food aid, is targeted the most for land grabbing contracts. 
Table 4. Top participants in food aid and land grabbing. Countries are ranked by frequency of their participation. Nine out of the top twenty countries (Ethiopia, Uganda, Kenya, India, Philippines, Peru, Mozambique, Zambia and Guatemala) are frequent recipients of aid and subject to land grabbing (compare Columns 3 and 5). India is the only country that is a major food aid donor and recipient, as well as a land grabbing investor and target.

\begin{tabular}{cccccc}
\hline & \multicolumn{2}{c}{ Food Aid } & & \multicolumn{2}{c}{ Land Grabbing } \\
\cline { 2 - 3 } \cline { 5 - 6 } Rank & Donor & Recipient & & Investor & Target \\
\hline 1 & USA & Ethiopia & & China & Cambodia \\
2 & China & Sudan & & India & Ethiopia \\
3 & South Korea & North Korea & Peru & Indonesia \\
4 & Canada & Bangladesh & & Malaysia & Laos \\
5 & Australia & Afghanistan & & USA & Peru \\
6 & Japan & Eritrea & & Ethiopia & Mozambique \\
7 & Italy & Uganda & & Cambodia & India \\
8 & EU & Haiti & & UK & China \\
9 & Egypt & Kenya & & Indonesia & Guinea \\
10 & Algeria & Honduras & & Canada & Zambia \\
11 & Denmark & India & & Japan & Ghana \\
12 & India & Philippines & France & Philippines \\
13 & Luxembourg & Peru & Mozambique & Kenya \\
14 & Spain & Mozambique & Netherlands & Senegal \\
15 & Syria & Zambia & Denmark & Malaysia \\
16 & Libya & Guatemala & Luxembourg & Tanzania \\
17 & Saudi Arabia & Bolivia & & Belgium & Guatemala \\
18 & France & El Salvador & & Spain & Madagascar \\
19 & Belgium & Tajikistan & & Laos & Uganda \\
20 & Switzerland & Mauritania & Saudi Arabia & Congo \\
\hline & & & & &
\end{tabular}

\subsection{Water Savings}

We find that food aid saved $12 \mathrm{~km}^{3} \cdot$ year $^{-1}$ of water in 2005. The water efficiency of food aid can be quantified by the volume of water saved to the volume of water embodied in aid. This ratio is $120 \%$. For international trade, the ratio of saving to the total water footprint of trade is $34 \%$. Interestingly, internal trade amongst African countries demonstrates the largest regional water efficiency of food trade [42]. Regional water savings from trade are 2.5-times greater than the total water footprint of regional food trade in Africa [42]. Thus, food aid is much more water-efficient than the global food trade system, but not as water-efficient as African regional trade. However, this is partly driven by large inefficiencies in agricultural production in a few African countries, highlighting the critical need to close these "yield gaps" [43]. 
Thus, there is a high water savings associated with food aid. This indicates that food aid is efficient from a water resources perspective. However, the food aid system is dependent on a single nation: the United States. In this way, the food aid system exemplifies the well-known trade-off in complex systems between system efficiency and system redundancy [44]. Redundancy is an essential component of resiliency in a complex system and has been suggested as a core tenet of sustainability [45].

A critical assumption underlying the water savings calculation is that recipient countries would produce the products domestically if aid were ceased. If this were the case, it would be akin to recipient countries engaging in local purchases (see Section 2.1 or Figure 2). Under this scenario, domestic production could be increased through either intensification (improved yields) or extensification (increase farm acreage) techniques [46]. Intensification practices can be sustainable with appropriate support and technology transfer to smallholder farmers; the vast majority of farms exist on less than two hectares of land in sub-Saharan Africa and, hence, are classified as smallholder [47]. Attempts to boost yields in sub-Saharan Africa have been slow, with mixed results that typically rely on increased fertilizer inputs [42,48], although there have been moderate successes in improving maize yields [49]. If countries were to promote extensification, it is likely that greenhouse gas emissions would increase due to deforestation [46]. Negative biodiversity impacts also typically accompany extensification, as much of the land is obtained by converting habitat to agricultural parcels [48]. Due to its high regional efficiency in terms of water resources [42], trade between African nations may be another complementary tool to enhanced agricultural production.

\subsection{Multivariate Regression Analysis}

To determine the key drivers of the water footprint of food aid, we perform multivariate linear regression (MLR) analysis on the donor and recipient water footprints. The donor MLR case identified five significant explanatory variables: flooding, drought, recipient frequency, control of corruption and total water footprint of national consumption. One variable was identified as a highly significant explanatory variable: the dependency ratio. The reduced model based on these significant explanatory variables is presented in Equation (4) as:

$$
\log \left[W F_{d}\right]=-3.34-0.30 x_{1}-1.28 x_{2}+0.08 x_{3}-0.92 x_{4}+2.06 x_{5}+0.99 x_{6}
$$

where $d$ is the donor country, $x_{1}$ is the flooding indicator from the World Resources Institute, $x_{2}$ is the drought indicator from WRI, $x_{3}$ is the dependency ratio from AQUASTAT, $x_{4}$ is the recipient frequency, $x_{5}$ is the control of corruption from the World Bank and $x_{6}$ is the total water footprint of national consumption from WaterStat. The reduced model returned an $R^{2}$ value of 0.3616. Figure 6 presents the $\log$ of the donor water footprint versus the log of the fitted values. 


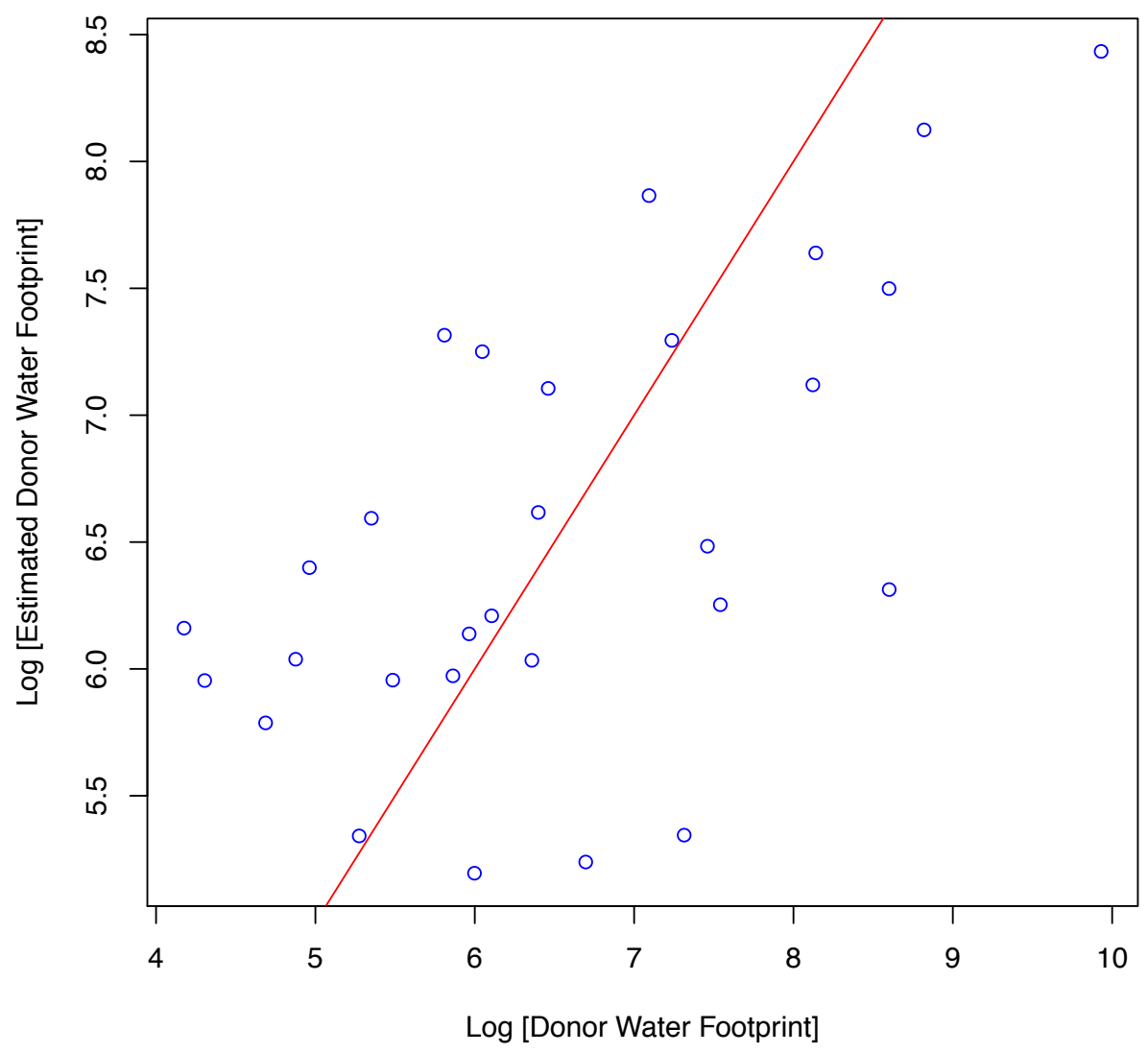

Figure 6. Multivariate linear regression results $\left(R^{2}=0.36\right)$ for the donor water footprint. The red line represents the 1:1 relationship between the regression estimate provided by Equation (4) and the calculated donor water footprints obtained in this study.

Both flooding and drought are environmental indicators that negatively correlate with the donor water footprint. It is suggested that donor countries are less susceptible to these environmental stresses that could potentially reduce agricultural production. The dependency ratio is a positive driver of donor water footprints. This ratio demonstrates a country's dependency on external water resources, especially those upstream [36]. High ratio countries are able to secure externally-sourced water, thereby procuring necessary water resources to maintain agricultural production. In turn, increased agricultural production may enable donor countries to contribute to food aid. Control of corruption is a political indicator that positively correlates with donor water footprints. This indicator highlights the degree to which the public domain remains free of influence from special interests [37]. The food aid program is a humanitarian effort. Countries showing high levels of control are able to contribute public resources as needed without impediment by private interests. The total water footprint of national consumption also positively correlates with donor water footprint. Large consumptive footprints reflect a country's interconnectedness to other countries via trade networks. Therefore, these countries already have the mechanisms in place to support food aid donations.

The recipient MLR case identified three significant variables: recipient frequency, investor frequency and agricultural land fraction. The reduced model based on these critical explanatory variables is presented in Equation (5) as: 


$$
\log \left[W F_{r}\right]=5.95+1.17 x_{4}+0.61 x_{7}+0.33 x_{8}
$$

where $r$ is the recipient country, $x_{7}$ is the investor frequency from land grabbing activities and $x_{8}$ is the agricultural land fraction from the World Bank. The reduced model returned an $R^{2}$ value of 0.51 . Figure 7 presents the log of the recipient water footprint versus the log of the fitted values.

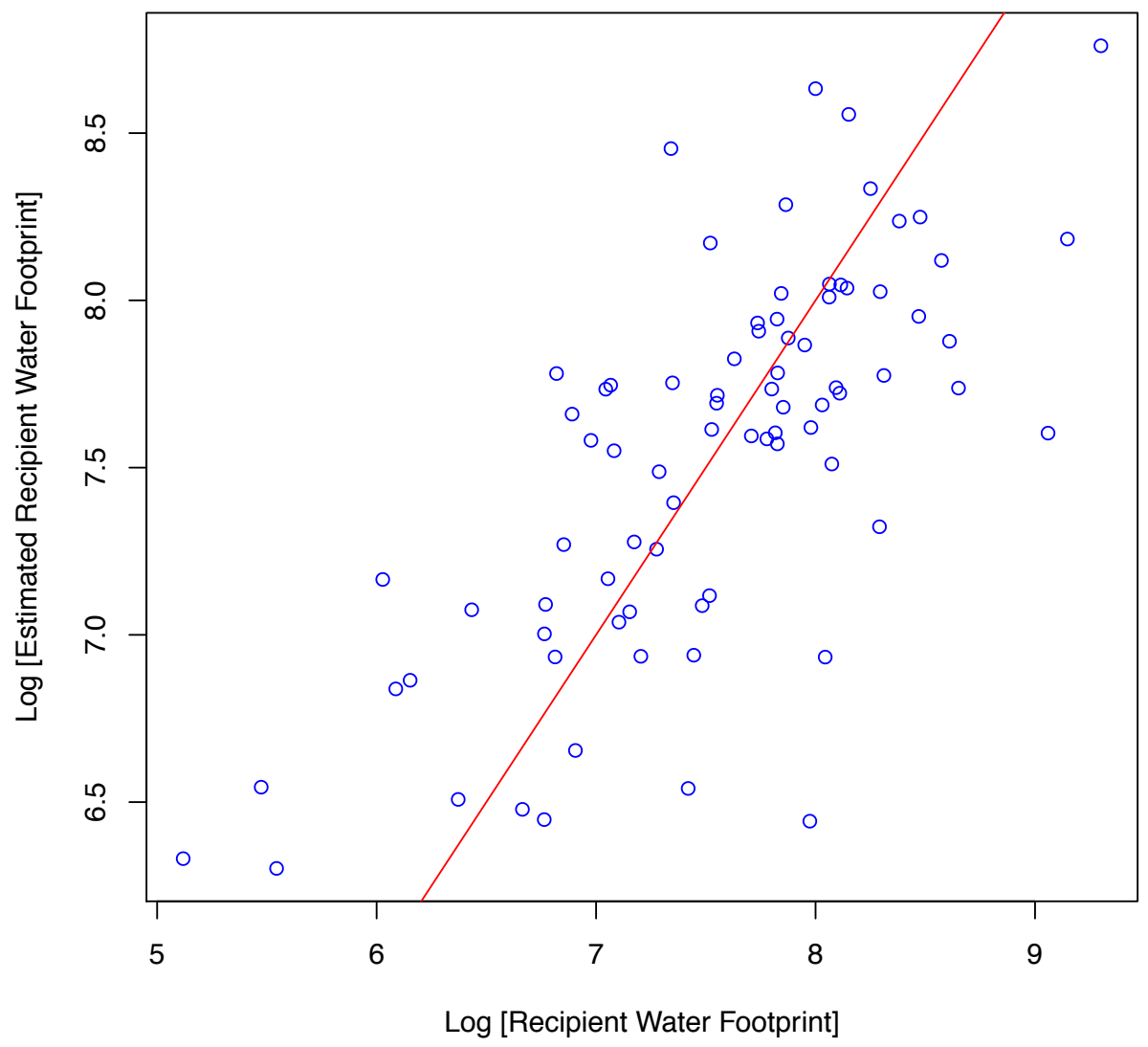

Figure 7. Multivariate linear regression results $\left(R^{2}=0.51\right)$ for the recipient water footprint. The red line represents the 1:1 relationship between the regression estimate provided by Equation (5) and the calculated donor water footprints obtained in this study.

Recipient frequency is a key explanatory variable for both donor and recipient water footprints. An increase in recipient frequency directly indicates a larger footprint for the country. This is an intuitive relationship given how water footprints are a function of commodity volume (see Equation (2)). Increases in frequency leads to an increase in the volume. However, the negative correlation of recipient frequency to the food aid donor water footprint in Equation (4) suggests that increases in frequency will lead to a decrease in a donor's water footprint. Investor frequency is a major contributor to estimating food aid recipient water footprints; there is a positive correlation between the two. Agriculture relies on primarily green and, to a lessor extent, blue water for production [2]. However, land grabbing results in a gain of these waters for the investor at the expense of the recipient country [50]. If countries retained the grabbed land and the water resources associated with it, they could realize the agricultural benefits for themselves. The agricultural land fraction is a positive driver of a recipient's food aid water footprint. The growth in agricultural areas results in higher water footprints for recipients. This phenomenon 
suggests that extensification could be occurring, but external support for food security via direct transfer food aid is still needed.

\section{Conclusions}

We quantified the water footprint of food aid for the first time. For the year 2005, the total water footprint of direct transfer food aid was $10 \mathrm{~km}^{3}$, which is approximately $0.5 \%$ of the water footprint of food trade and $2.0 \%$ of the water footprint of land grabbing. Thus, this study highlights that the water footprint of food aid comprises a relatively insignificant fraction of the water footprint of the global food system. However, despite being small in terms of the total volume transferred, food aid and its embodied water resources provide a critical resource during times of humanitarian crises. Importantly, this paper, which quantified the water footprint of food aid, contributes to our understanding of the equity of the water footprint of humanity, an important goal of sustainable water management [17].

Multivariate regression analyses between the water footprint of food aid and key variables indicate that donor and recipient footprints are driven by primarily different characteristics. In particular, the propensity for flooding and drought, as well as the dependency ratio, control of corruption and the water footprint of national consumption are key variables for determining a donor's water footprint. Conversely, investor frequency for land grabbing activities and the agricultural land fraction have been identified as key variables for estimating a recipient's water footprint. The recipient frequency serves as a critical variable for both footprint estimates. Although multivariate regression relationships have been obtained, they are only the start. Future research should employ tools of causal inference to more accurately understand mechanistic relationships in the global food system. Going forward, research efforts should evaluate the causal implications of food aid for food and water security in recipient nations, particularly in light of recent findings that food aid actually leads to more violence $[7,8]$.

The United States is the single largest donor of food aid and contributes $82 \%$ of the total water footprint. The countries that receive the most water embodied in aid are Ethiopia, Sudan, North Korea, Bangladesh and Afghanistan. Significantly, many of the countries that are major recipients of food aid also have their land grabbed through long-term contracts. Future research should evaluate the implications of land grabbing for political stability and food security in the grabbed country, in order to better understand links to the food aid system. It is critical to determine the causal relationships between land grabbing, food aid and food security in developing countries, to effectively guide humanitarian relief efforts and international policy.

\section{Acknowledgments}

We thank the World Food Programme for making the food aid data available. We thank the Water Footprint Network for providing the WaterStat database. The work was partially developed within the framework of the Panta Rhei Research Initiative of the International Association of Hydrological Sciences (IAHS). 


\section{Author Contributions}

Nicole Jackson collected and analyzed the data. Nicole Jackson, Megan Konar, and Arjen Hoekstra designed the research and wrote the paper. All authors approve the final manuscript.

\section{Conflicts of Interest}

The authors declare no conflict of interest.

\section{References}

1. Hoekstra, A.Y. The global dimensions of water governance: Why the river basin approach is no longer sufficient and why cooperative action at global level is needed. Water 2011, 3, 21-46.

2. Hoekstra, A.Y.; Mekonnen, M.M. The water footprint of humanity. Proc. Natl. Acad. Sci. USA 2012, 109, 3232-3237.

3. Dalin, C.; Konar, M.; Hanasaki, N.; Rinaldo, A.; Rodriguez-Iturbe, I. Evolution of the global virtual water trade network. Proc. Natl. Acad. Sci. USA 2012, 109, 5989-5994.

4. Rulli, M.C.; D’Odorico, P. The water footprint of land grabbing. Geophys. Res. Lett. 2013, 40, 6130-6135.

5. Rulli, M.C.; Saviori, A.; D'Odorico, P. Global land and water grabbing. Proc. Natl. Acad. Sci. USA 2013, 110, 892-897.

6. Oxfam. Food Aid: A Critical Program Ripe for Reform. Available online: http://www.oxfamamerica.org/take-action/campaign/food-farming-and-hunger/food-aid/ (accessed on 1 February 2015).

7. Crost, B.; Felter, J.; Johnston, P. Aid Under Fire: Development Projects and Civil Conflict. Am. Econ. Rev. 2014, 104, 1833-1856.

8. Nunn, N.; Qian, N. U.S. Food Aid and Civil Conflict. Am. Econ. Rev. 2014, 104, 1630-1666.

9. U.S. Agency for International Development. Food Aid Reform. Available online: http://www.usaid.gov/foodaidreform (accessed on 1 February 2015).

10. Shaw, D.J. The UN World Food Programme And The Development Of Food Aid; Palgrave: New York, NY, USA, 2001.

11. Hoekstra, A.Y. (Ed.) Virtual water trade. In Proceedings to the International Expert Meeting on Virtual After Trade, Delft, The Netherlands, 12-13 December 2002.

12. Hoekstra, A.Y.; Chapagain, A.K. Globalization of Water: Sharing the Planet's Freshwater Resources; Blackwell: Oxford, UK, 2008.

13. Mekonnen, M.M.; Hoekstra, A.Y. The green, blue and grey water footprint of crops and derived crop products. Hydrol. Earth Syst. Sci. 2011, 15, 1577-1600.

14. Hoekstra, A.Y.; Hung, P.Q. Globalisation of water resources: International virtual water flows in relation to crop trade. Glob. Environ. Chang. 2005, 15, 45-56.

15. Hanasaki, N.; Inuzuka, T.; Kanae, S.; Oki, T. An estimation of global virtual water flow and sources of water withdrawal for major crops and livestock products using a global hydrological model. J. Hydrol. 2010, 384, 232-244. 
16. Konar, M.; Dalin, C.; Suweis, S.; Hanasaki, N.; Rinaldo, A.; Rodriguez-Iturbe, I. Water for food: The global virtual water trade network. Water Resour. Res. 2011, doi:10.1029/2010WR010307.

17. Hoekstra, A.Y. Sustainable, efficient and equitable water use: The three pillars under wise freshwater allocation. WIREs Water 2014, 1, 31-40.

18. Rogers, P.; de Silva, R.; Bhatia, R. Water is an economic good: How to use prices to promote equity, efficiency, and sustainability. Water Policy 2002, 4, 1-17.

19. Chapagain, A.K.; Hoekstra, A.Y.; Savenije, H.H. Water saving through international trade of agricultural products. Hydrol. Earth Syst. Sci. 2006, 10, 455-468.

20. Aldaya, M.M.; Allan, J.A.; Hoekstra, A.Y. Strategic importance of green water in international crop trade. Ecol. Econ. 2010, 69, 887-894.

21. Konar, M.; Dalin, C.; Hanasaki, N.; Rinaldo, A.; Rodriguez-Iturbe, I. Temporal dynamics of blue and green virtual water trade networks. Water Resour. Res. 2012, doi:10.1029/2012WR011959 .

22. Allan, T. Fortunately there are substitutes for water: Otherwise our hydropolitical futures would be impossible. In Proceedings of the Conference on Priorities for Water Resources Allocation and Management, Southampton, UK, July 1993; Volume 2, pp. 13-26.

23. Tamea, S.; Carr, J.; Laio, F.; Ridolfi, L. Drivers of the virtual water trade. Water Resour. Res. 2014, $50,17-28$.

24. Food Aid Information System Online Database. Available online: http://www.wfp.org/fais/ (accessed on 5 January 2015).

25. World Food Programme. World Food Programme Quantity Reporting. Available online: http://www.wfp.org/fais/reports/quantities-delivered-two-dimensional-report (accessed on 5 January 2015).

26. World Food Programme. Food Information System: Aggregations and Groupings; World Food Programme: Rome, Italy, 2015.

27. Lowder, S.; Raney, T. Food Aid: A Primer ESA Working Paper No. 05-05. In Technical report, Agricultural and Development Economics Division The Food and Agriculture Organization of the United Nations; Food and Agriculture Organization of the United Nations: Rome, Italy, 2005.

28. Hoekstra, A.Y.; Chapagain, A.K.; Aldaya, M.M.; Mekonnen, M.M. The Water Footprint Assessment Manual: Setting the Global Standard; Earthscan: London, UK, 2011.

29. Yang, H.; Wang, L.; Abbaspour, K.; Zehnder, A. Virtual water trade: An assessment of water use efficiency in the international food trade. Hydrol. Earth Syst. Sci. 2006, 10, 443-454.

30. Konar, M.; Hussein, Z.; Hanasaki, N.; Mauzerall, D.L.; Rodriguez-Iturbe, I. Virtual water trade flows and savings under climate change. Hydrol. Earth Syst. Sci. 2013, 17, 3219-3234.

31. Wichelns, D. The role of 'virtual water' in efforts to achieve food security and other national goals, with an example from Egypt. Agric. Water Manag. 2001, 49, 131-151.

32. Krugman, P.; Obstfeld, M. International Economics: Theory and Policy, 8th ed.; Addison-Wesley: Upper Saddle River, NJ, USA, 2009; p. 687.

33. Gassert, F.; Reig, P.; Luo, T.; Maddocks, A. Working Paper: Aqueduct Country and River Basin Ranking-A Weighted Aggregation of Spatially Distinct Hydrological Indicators; Technical Report; World Resources Institute: Washington, DC, USA, 2003. 
34. Reig, P.; Shiao, T.; Gassert, F. Working Paper: Aqueduct Water Risk Framework; Technical Report; World Resources Institute: Washington, DC, USA, 2013.

35. Gassert, F.; Reig, P.; Shiao, T.; Landis, M.; Luck, M. Working Paper: Aqueduct Global Maps 2.0; Technical Report; World Resources Institute: Washington, DC, USA, 2013.

36. FAO. AQUASTAT Website. Available online: http://www.fao.org/nr/water/aquastat/main/index.stm (accessed on 15 January 2015).

37. World Bank. Indicators Online Database. Available online: http://data.worldbank.org/data-catalog/ world-development-indicators (accessed on 15 January 2015).

38. Kaufmann, D.; Kraay, A.; Mastruzzi, M. The Worldwide Governance Indicators: Methodology and Analytical Issues; Technical Report, World Bank Policy Research Working Paper No. 5430; World Bank: Washington, DC, USA, 2010.

39. LMGO. The Land Matrix: Get the Detail. Available online: http://www.landmatrix.org/en/getthe-detail/ (accessed on 5 January 2015).

40. Krzywinski, M.I.; Schein, J.E.; Birol, I.; Connors, J.; Gascoyne, R.; Horsman, D.; Jones, S.J.; Marra, M.A. Circos: An information aesthetic for comparative genomics. Genome Res. 2009, 19, 1639-1645.

41. Food and Agriculture Organization of the United Nations Statistics Division. Trade-Crops and Livestock Products. Available online: http://faostat3.fao.org/download/T/TP/E (accessed on 7 February 2015).

42. Konar, M.; Caylor, K. Virtual water trade and development in Africa. Hydrol. Earth Syst. Sci. 2013, 17, 3969-3982.

43. Foley, J.A.; Ramankutty, N.; Brauman, K.A.; Cassidy, E.S.; Gerber, J.S.; Johnston, M.; Mueller, N.D.; O’Connell, C.; Ray, D.K.; West, P.C.; et al. Solutions for a cultivated planet. Nature 2011, 478, 337-342.

44. Schweitzer, F.; Fagiolo, G.; Sornette, D.; Vega-Redondo, F.; Vespignani, A.; White, D.R. Economic Networks: The New Challenges. Science 2009, 325, 422-425.

45. Levin, S.; Sheshinski, E.; Barrett, S.; Aniyar, S.; Baumol, W.; Bliss, C. Resilience in natural and socioeconomic systems. Environ. Dev. Econ. 1998, 2, 221-262.

46. Tilman, D.; Balzer, C.; Hill, J.; Befort, B.L. Global food demand and the sustainable intensification of agriculture. Proc. Natl. Acad. Sci. USA 2011, 108, 20260-20264.

47. Vanlauwe, B.; Coyne, D.; Gockowski, J.; Hauser, S.; Huising, J.; Masso, C.; Nziguheba, G.; Schut, M.; Asten, P.V. Sustainable intensification and the African smallholder farmer. Curr. Opin. Environ. Sustain. 2014, 8, 15-22.

48. Tilman, D.; Fargione, J.; Wolff, B.; D’Antonio, C.; Dobson, A.; Howarth, R.; Schindler, D.; Schlesinger, W.H.; Simberloff, D.; Swackhamer, D. Forecasting Agriculturally Driven Global Environmental Change. Science 2001, 292, 281-284.

49. Sanchez, P.A.; Denning, G.L.; Nziguheba, G. The African Green Revolution moves forward. Food Secur. 2009, 1, 37-44. 
50. Rulli, M.C.; Saviori, A.; D’Odorico, P. Global land and water grabbing. Proc. Natl. Acad. Sci. USA 2013, 110, 892-897.

(c) 2015 by the authors; licensee MDPI, Basel, Switzerland. This article is an open access article distributed under the terms and conditions of the Creative Commons Attribution license (http://creativecommons.org/licenses/by/4.0/). 